\title{
Complexity Versus Availability for Fusion: The Potential Advantages of Inertial Fusion Energy
}

\author{
L. J. Perkins
}

Sptember 5, 1996

This is an informal repert intended primarily for internal or limited extemal diatribution. The opinions and conclusions etated sre those of the author and may or may not be thece of the Laborabry.

Work performed under the aupices of the U.S. Department of Energy by the Lawrence Livermere National Laboratory under Contract W-7405-Eng-48. 


\section{DISCLAIMRR}

This document was prepared as an account of work sponsored by an agency of the United States Covernment. Nelther the United States Covernment nor the University of Celifornis nor any of their eonployees, makes any warranty, express or implied, or asoumes any legal bisblity or reeponsibility for the eccuracy, completeneis, or usefulness of eny information, apperatus, product, or procese disclosed, or represents that its use would not infringe privately owned rights. Refarence herein to any specific conmerclal product, proces, or survice by trade neme, trademark, manuficturer, or otherwise, does not necesanily conetitute or imply its endorsement, recommendation, or favoring by the United States Government or the Univeralty of California. The views and opinions of authors expresed herein do not necesearlly state or refiect those of the United States Government or the University of California, and shall not be ued for advertiding or product endorsement purposes.

This report has been reproduced directly from the best available copy.

Availuble to DOE and DOB contractors from the Office of Scientific and Technical Information P.O. Box 62, Onk Ridge, TN 37831

Prices available from (615) 576-8401, FTS 626-8401

Available to the public from the

National Technical hrformation Service

U.S. Department of Commence

5285 Port Royal Rd.

Springfield, VA 22161 


\title{
Complexity Versus Availability for Fusion: The Potential Advantages of Inertial Fusion Energy
}

\author{
L. John Perkins \\ Lawrence Livermore National Laboratory
}

September 5, 1996

\begin{abstract}
Synopsis
Probably the single largest advantage of the inertial route to fusion energy (IFE) is the perception that its power plant embodiments could achieve acceptable capacity factors. This is a result of its relative simplicity, the decoupling of the driver and reactor chamber, and the potential to employ thick liquid walls. We examine these issues in terms of the complexity, reliability, maintainability and, therefore, availability of both magnetic and inertial fusion power plants and compare these factors with corresponding scheduled and unscheduled outage data from present day fission experience. We stress that, given the simple nature of a fission core, the vast majority of unplanned outages in fission plants are due to failures outside the reactor vessel itself. Given we must be prepared for similar outages in the analogous plant external to a fusion power core, this puts severe demands on the reliability required of the fusion core itself. We indicate that such requirements can probably be met for IFE plants. We recommend that this advantage be promoted by performing a quantitative reliability and availability study for a representative IFE power plant and suggest that databases are probably adequate for this task.
\end{abstract}

\section{Background and Motivation}

Our perception of the commercial attractiveness of future fusion power plants is somewhat clouded by the following uncertainties:

1. The uncertainty that the physics and technology will work as projected on paper today.

2. The uncertainty in the capital cost of the extrapolated technology.

3. The issue of complexity, reliability, maintainability - and, therefore, the uncertainty in the availability - of the fusion power core.

That is: Will they work, how much will they cost, will they break and can they be easily repaired? 
The first category of uncertainty is the reason we have on-going research and development programs. So ultimately we will know whether the physics and technology "works" before committing to commercial construction. The uncertainty in the second category - i.e., uncertainty in extrapolated capital costs - is more problematic, not least because of the absence of any real data. The prospective International Thermonuclear Experimental Reactor (ITER), for example, is a one-off, state-of-the-art system with little substantive prior cost database to draw on. Consequently, uncertainties in this category are probably around a factor of two for next step fusion power devices like ITER* and probably more for our ultimate power reactors. Presumably, such uncertainties will decrease as further development is performed.

However, it is probably the third category which is perceived to be the most serious concern facing prospective power plants of the conventional magnetic fusion energy (MFE) class. Such devices - e.g., the tokamak and stellarator - are characterized by large superconducting magnets, solid first walls and many complex integrated components within the vacuum-tight fusion power core. It is here that IFE plant concepts potentially offer the biggest advantage and, therefore, an advantage we should seek to quantify as far as possible. In this discussion paper, we examine this central issue of complexity, reliability, maintainability and, therefore, availability - referred to as "CRAM" in the remainder of the text.

MFE reactor design studies have been performed in recent years which suggest that commercial reactors based on various extrapolated advanced physics assumptions would exhibit a cost-of-electricity of about $\sim 1.5$ to 2 times that of today's better experience fission plants [see, for example, Refs. 2, 3, 4]. If our projected reactors are, indeed, only, say, $50 \%$ more expensive than present day fission then conventional MFE fusion might appear to have some potential in the energy marketplace of the future. On the face of it, this would seem to be a reasonable standpoint to take. Why then, the disquiet over recent years regarding the state of our commercial MFE reactor product [5 - 15]? It suggests that, in our hearts, we either don't really believe these numbers, or, at least, are concerned that the real situation will be considerably worse because of, at least, the CRAM prospects.

We note that the functional dependence of the cost-of-electricity (COE) resulting from most reactor studies to date are determined almost entirely by the capital cost projections for the plant. The CRAM aspect is sidestepped either from reluctance or, more usually, from the lack of easily identified formalisms for obtaining quantitative results. Accordingly, in today's reactor

\footnotetext{
" ITER has an "official" cost of $\sim \$ 6 \mathrm{~B}[1]$ but is considered by many to be a machine in the $\$ 10 \mathrm{~B}+$ class. No detailed costing uncertainty analysis has yet been performed for this device.
} 
studies, plant capacity factors are typically supplied as input constants with little or no regard to the CRAM aspects of the particular design.

In general, the uncertainty in the CRAM for a conventional MFE plant is large and is probably the largest single contributor to the uncertainty in the projected COE. For example, an ITER maintenance study performed in 1991 indicated that, in the event of a serious failure of a toroidal field coil, it would take in the range 3-5 years to replace this magnet once the machine had been operating for 1 year [16]. There is no indication from our reactor studies that a commercial tokamak reactor would be substantially less complex than ITER, even those based on extrapolated advanced physics. Thus, the perception by future customers that a conventional MFE fusion plant is not maintainable in a finite time frame suggests that they might be considered non-viable on this aspect alone. That is, irrespective of our projections of potential advances in the physics and resulting reductions in $\mathrm{COE}$ through lower capital cost, the CRAM prospects alone may be considered simply a go/no-go issue by our future customers.

Therefore, not only could we argue that the COE for projected IFE reactors may be lower than that of the conventional MFE approach [17] but, rather, that our IFE power plant concepts could conceivably pass the irreducible test: - That potential customers are sufficiently confident that minimum acceptable capacity factors are attainable that they would be willing to entertain the possibility of ordering one.

One other related comment is in order here. Economy-of-scale principles can be used to reduce the projected COE of both MFE and IFE plants [see, for example, Refs. 2, 18-21]. Such studies typically indicate that reactors constructed in unit sizes significantly larger than $1 \mathrm{GW}$ may approach a costof-electricity competitive with advanced fission projections. However, the problem of CRAM may negate that conclusion for MFE. While the utility structure in the next century may be different from today, and multi-GW electricity reservations may become the norm, certainly in the world as a whole, it must be considered questionable that any utility - private, public or government-owned - will invest in a large, single heat source which is perceived to be vulnerable to frequent outages and significant downtimes for repair. Hydroelectric plants are commonly found in multi-GWe sizes. However, these have the crucial difference of redundancy where each plant has the modularity of parallel water feeds to a number of independent turbine-generator sets. Therefore, with regard to redundancy, large, multiGWe IFE plants with multiple, maintainable target chambers presents an additional potential advantage. Of course, they would typically be based around a single driver but we believe this can be sufficiently reliable based on present accelerator operating experience. 


\section{Fission Experience and Relevance to Fusion Projections}

Presently operating fission plants provide the best real data we have to guide our thinking on capacity factors ${ }^{*}$ of potential fusion power plants. Accordingly from availability and outage data published over the past three years [22-29] we can make the following observations of relevance to fusion:

There are 108 present fission plants in the US each with more than three years of operating experience [29]. The capacity factor performance for each of these plants were recently published by Blake [28]. Taking Blake's raw data, and, neglecting the worst three plants ${ }^{*}$ which otherwise would appreciably skew standard deviations, Fig. 1 gives a summary of their three-year-averaged (1993-95) capacity factors (CF) at design electric rating :

Fig. 1. Summary of Three Year (1993-95) Capacity Factors for 105 out of 108* US Fission Plants at Design Electrical Rating (raw data from Blake [28])

- Median capacity factor (CF) at design electric rating $=79.0 \%$

- Mean $\mathrm{CF}=75.4 \%$, with a standard deviation of $\pm 12.3 \%$

- Best is Prairie Island 1 (530MW $\mathrm{e}$ PWR) with $\mathrm{CF}=90.6 \%$.

- Worst ${ }^{*}$ is Dresden 2 (794MWe BWR) with CF $=43.1 \%$

- 23 units (22\% of total) have $\mathrm{CF}>85 \%$

- 80 units ( $76 \%$ of total) have $\mathrm{CF}>70 \%$

- 8 plants $(7.6 \%$ of total) have $\mathrm{CF}<50 \%$

- Small reactors $(\leq 700 \mathrm{MW})$ as a group had median $\mathrm{CF}=84.3 \%$

- Large reactors $(\geq 1020 \mathrm{MW})$ as a group had median $\mathrm{CF}=78.1 \%$

* Bottom three plants from the 108 US group were dropped from averaging procedures here as they skew averages and standard deviations appreciably. These plants and capacity factors are: Indian Point-3 (10.5\%), Browns Ferry-1 (2.7\%), and Browns Ferry-2 (0\%)

\footnotetext{
"A note on definition of availability and capacity factor: "Availability" is the percentage of time that a plant is operational and available to produce power even though, for reasons of load following and grid demands, it may not do so at its full design electric rating (DER). "Capacity factor" is availability multiplied by the averaged fraction of DER output over the availability period. Capacity factors of fission plants are usually quoted as three year averages to smooth out year-to-year variations.

these plants and capacity factors are: Indian Point-3 (10.5\%), Browns Ferry-1 (2.7\%), and Browns Ferry-2 (0\%)
} 
It is instructive to select four of these plants to examine the basis for these capacity factors in terms of both scheduled and unplanned outages. Accordingly, extracting data from Refs 22-27, and 30, Table 1 summarizes the outage data and contributions to the unavailability for the best US fission plant (Prairie Island 1 with $\mathrm{CF}=90.6 \%$ ), a plant around the mean (Robinson 2 with $\mathrm{CF}=76.0 \%$ ) and two poor performers (Sequoyah 2 with $\mathrm{CF}=46.9 \%$, and Quad Cities 2 with $C F=46.4 \%$ )

From Table 1, we can draw the following observations and inferences:

- A typical scheduled outage for a well performing fission plant is $\sim 6-8$ weeks every $\sim 18$ months, coupled with an average shutdown/startup period before/after the outage at fractional power of $\sim 28$ days total. This would result in an averaged capacity factor (CF) of $\sim 86 \%$ providing there were no other unplanned outages. Note from above, the industry median CF of all plants is $\sim 79 \%$ while about one-fifth of the 105 US plants have a CF better than $85 \%$.

- If only refueling was to be carried out with no other serial maintenance activities, then, in an 18 month cycle, typical theoretical unavailabilities would be $\sim 2$ weeks for core head removal and changeout of fuel assemblies, and $\sim 2-3$ weeks start/up shutdown. This would give a theoretical maximum capacity factor of $\sim 94 \%{ }^{*}$. Note that MFE fusion plants are effectively required to undergo a "fueling" outage due to blanket replacement (see below); IFE plants with thick liquid walls are not.

- Refueling is one of the major activities during a scheduled outage but not the only one. In some cases, it's not necessarily a rate-limiting critical step. Other than refueling and $10 \mathrm{yr}$ standard vessel inspections, all other major routine maintenance activities take place outside the core, i.e. primary loop and balance-of-plant. Very importantly, the latter would be expected to apply to analogous systems in fusion plants outside the fusion power core even in the absence of a refueling outage.

- One major reason for the differences in capacity factors between Prairie Island $1(90.6 \%)$ and Robinson $2(76 \%)$ is that the former had only one standard scheduled fueling outage in the 3-year 1993-95 assessment period (in the. middle) while the latter had two (one near the beginning and one near the end).

- The typical projected fluence lifetime of an MFE fusion reactor blanket is $\sim 10-15 \mathrm{MW}-\mathrm{yr} / \mathrm{m}^{2}$, i.e. a lifetime of approximately 3 full power years at typical projected neutron wall loading. Therefore, a typical blanket changeout

\footnotetext{
- Actual outages of this onder have recently been recently achieved at Houston Lighting and Power due to other time-critical routine maintenance being performed on-line [31]
} 
Table 1. Scheduled and Unscheduled Outage Contributions for Four Representative US Fission Plants

\begin{tabular}{|c|c|c|}
\hline $\begin{array}{l}\text { Plant and } \\
\text { Capacity Factora }\end{array}$ & $\begin{array}{c}\text { Scheduled Outages and Major } \\
\text { Activities 1993-95 }\end{array}$ & $\begin{array}{l}\text { Unscheduled and Over-Running } \\
\text { Scheduled Outages 1993-95 }\end{array}$ \\
\hline $\begin{array}{l}\text { Prairie /sland 1 } \\
\text { PWR, 530NWe } \\
90.6 \%, 1 \mathrm{st} / 105\end{array}$ & $\begin{array}{l}\text { June 94, 44days: } \\
\text { RF", 10yr vessel ISI", main gen. inspect., repl of } \\
\text { MSR steam bundles, SGEC, } 40 \text { MOV tests, } \\
\text { (Total coastdown/startup days b: } 42 \text { ) }\end{array}$ & $\begin{array}{l}\text { 1993-95: 21days. Miscell. items external to core } \\
\text { Note: Only one refueling cycle 1993-95 }\end{array}$ \\
\hline $\begin{array}{l}\text { Robinson 2 } \\
\text { PWR, 700MW } \\
76.0 \%, 66 \text { th } / 105\end{array}$ & $\begin{array}{l}\text { Sept 93, 63days: } \\
\text { RF*, SL, SGEC, RCP replacement, RHR maint. } \\
\text { April 95, } 56 \text { days: } \\
\text { RF"(tull core offload), SGEC, MOV tests, turbine } \\
\text { inspections, EDG overhaul } \\
\text { (Total coastdown'startup days b: }, 56 \text { ) }\end{array}$ & $\begin{array}{l}\text { 1993-95: 88days. Miscell. items extemal to core } \\
\text { Note: Two standard refueling cycles 1993-95 }\end{array}$ \\
\hline $\begin{array}{l}\text { Sequoyeh } 1 \\
\text { PWR, 1148MWe } \\
46.9 \%, 101 \mathrm{st} / 105\end{array}$ & $\begin{array}{l}\text { March 93, 63days: } \\
\text { RF*, LPT replacement, MSRV inspection, ILRT", } \\
\text { SGEC, RCP replacement, 1Oyr vessel ISI, RHR pump } \\
\text { motor replacement } \\
\text { Sept 95, 60days: } \\
\text { RF, SG maint., chem d } 4 \text { SG, RCP repl., condenser } \\
\text { servicing, RHR pump motor servicing, LPT } \\
\text { inspection, erosion(corrosion piping mods } \\
\text { (Total coastdown/startup days b: -56) }\end{array}$ & $\begin{array}{l}\text { 1993-94, 334days: } \\
\text { Erosionvorrosion repairs on secondary side of SG } \\
\text { 1993-95: 68days on other miscell. items extemal to } \\
\text { core }\end{array}$ \\
\hline $\begin{array}{l}\text { Quad Clties } 2 \\
\text { BWR, } 789 \mathrm{MW} \\
46.4 \%, 102 \mathrm{nd} / 105\end{array}$ & $\begin{array}{l}\text { March 93, 84days: } \\
\text { RF, ILRT, RCIC pump replacement, shroud access } \\
\text { cover replacement", system valve work" } \\
\text { March 94, 76days: } \\
\text { RF, miscell plant maint } \\
\text { March 95, 126days: } \\
\text { RF (full core offioad), tur overhaul, gen inservice } \\
\text { inspection, tonus surface recoat } \\
\text { Total coastdown/startup days b: }, 84 \text { ) }\end{array}$ & $\begin{array}{l}\text { 1993-95: } 216 \text { days } \\
\text { HPCl turbine blowip. Other miscell. items extemal to } \\
\text { core } \\
\text { March 95: Tonus surface recoat (extended expected } \\
80 \text { days schd. outage to } 126 \text { days, but this wes } \\
\text { planned) } \\
\text { Note: - Three standard outages in } 3 \text { years. } \\
\text { - Regular outages are taking } 80 \text { days rather } \\
\text { than } 50-60 \text { days of better performing plants }\end{array}$ \\
\hline
\end{tabular}

${ }^{*}=$ Critical path task. a = 3 year capacity factor at design electrical rating, 1993-95. $b=$ Total days for SU/SD 1993-95 at average of $50 \%$ design electrical rating. RF - Refueling; ISI - Inservice inspection; MSR - Moisture separator reheater; SG - Steam generator; SGEC - Steam generator eddy current testing; MOV motor operated valves; SL - Sludge lancing of steam generators; RCP - Reactor coolant pump; RHR - Residual heat removal system; EDG - Emergency diesel generator, LPT - Low press turbine; MSRV - Main steam relief valve; ILRT - Integrated leak rate testing;

RCP - Reactor coolant pump; RCIC - Reactor core isolation cooling system; HPCl - High pressure coolant injection 
schedule might be $50 \%$ of the modules every 18 months. This is a similar maintenance schedule to a fission refueling outage. However, to be competitive in outage time, the fusion blanket changeout itself would have to be completed in $\sim 2$ weeks including torus ingress. This is not required in a thick liquid wall IFE plant. Note also, that the lifetime of fission fuel is typically $\geq 33,000 \mathrm{MW}_{\text {th }}$-days/ton. By comparison, taking typical design and operating parameters for ARIES-II-like vanadium blankets [3, 32], yields an equivalent lifetime for an MFE vanadium blanket of $\sim 18,000 \mathrm{MW}_{\text {th-days/ton, }}$ necessitating the changeout of about $80 \%$ additional fusion core mass for the same thermal power lifetime.

- Fission outages greater than about $20 \%$, i.e. capacity factors less than about $80 \%$, are usually due to either unplanned outages or over-running scheduled maintenance (Table 1). However, some plants have scheduled outages more frequently than every $\sim 18$ months. For example, in Table 1 , Quad Cities-2 plant is on 1 year refueling cycles due to the nature of their utility grid structure and had three such cycles during the 1993-95 capacity factor assessment period. Thus even with no unscheduled downtime, their ideal outages would be greater than $20 \%$. In fact, this plant has always been unable to keep its scheduled refueling outages to 40 days each, usually being at least double this (Table 1). Coupled with significant unscheduled outages in the balance-of-plant - e.g. over 200 days due to a blown high pressure coolant injection turbine - gave a composite three year capacity factor of only $\sim 46 \%$

- The vast majority of unplanned (scram) outages in fission plants are due to failures in systems outside the fission vessel, i.e. in the primary loop and balance-of-plant. Again, these would be expected to apply to analogous systems in fusion plants outside the fusion power core.

- The overall implication of these data is an extreme demand on the scheduled and, in particular, unscheduled outage requirements for the fusion power core of an MFE reactor, (i.e. cryostat, PF magnets, TF magnets, vacuum vessel, shield, blankets, divertors, etc.) and its fusion-specific auxiliary systems (i.e., fueling, heating, current-drive, vacuum, cryogenics, etc.). The same demands are also true in aggregate for the core and fusion-auxiliary systems of an IFE plant (i.e. driver, beam transport, chamber and fuel factory), but, due to their decoupling and individual maintainability, we should realize a significant advantage in this area.

\section{CRAM Issues for MFE and IFE.}

IFE provides a route to a power plant embodiment which is fundamentally different in many respects from that of the standard MFE class of concepts. There are no large, expensive superconducting magnets that are 
exposed to potentially damaging fusion radiation. This unique feature allows lifetime fusion chambers to be designed with renewable liquid coolants facing the targets [21, 33, 34], instead of solid, vacuum-tight walls that must be renewed on a frequent basis due to radiation damage. The relative advantage that this feature affords the core of an ICF power plant (i.e. the chamber) cannot be overstated relative to the availability issue.

Moir [34] has studied the quantitative advantages of liquid walls and suggests a resulting tangible reduction in COE. His analyses indicate a saving of $\sim 27 \%$ in the COE accruing from the impact on capital costs ( - $3 \%)$, blanket replacement costs $(\sim-12 \%)$ and capacity factor $(\sim-12 \%)$. Moir suggests that liquid protection will increase capacity factors by $\sim 12 \%$ by reducing scheduled and unscheduled downtimes to replace damaged blanket modules.

For a qualitative view of CRAM issues for MFE power plants, Figs. 2 and 3 show details of the design, assembly and maintenance of two in-vessel systems for ITER, namely the blanket and divertor [35]. We note these are not necessarily final design configurations for ITER nor are they necessarily fully representative of an ultimate power reactor embodiment. Nonetheless, ITER must be considered the best guide we have to date of a serious engineering design effort for an MFE reactor and we should note carefully the engineering complexities evident in Fig. 2 and 3. Note from above that, to remain competitive with fission, we must be able to perform scheduled maintenance on such configurations in a commercial reactor configuration within a $\sim 2$ week period every $\sim 18$ months. This is notwithstanding scheduled maintenance on other components of the fusion power core (shields, vacuum vessels, magnets, etc.).

In the case of unscheduled outages, the required reliability of individual blanket segments is very high. Take, for example, a typical MFE blanket system with 16 sectors and 9 blanket segments per sector. Table 2 . illustrates the required reliability of each of the 144 segments - i.e. required mean-time-between-failures, MTBF - if the blanket system is to contribute no more than $5 \%$ to the total unscheduled outage of the plant. This is shown as a function of the mean-time-to-repair MTTR, where the total blanket outage risk is given approximately by:

$$
\text { OutageRisk }=1-\prod_{i=1}^{n}\left(1+M_{T T R} / M T B F_{i}\right)^{-1}
$$

where $n$ is the number of blanket segments. Two observations here: First, with a breaker-to-breaker mean-time-to-repair (MTTR) of, say, one month probably near the minimum feasible for an unplanned blanket failure inside the high vacuum enclosure - the required reliability of each sector is $\sim 240$ full power years!. Second, even so, our example $5 \%$ outage risk due to the blanket alone is probably too large given the multiplicity of other systems 

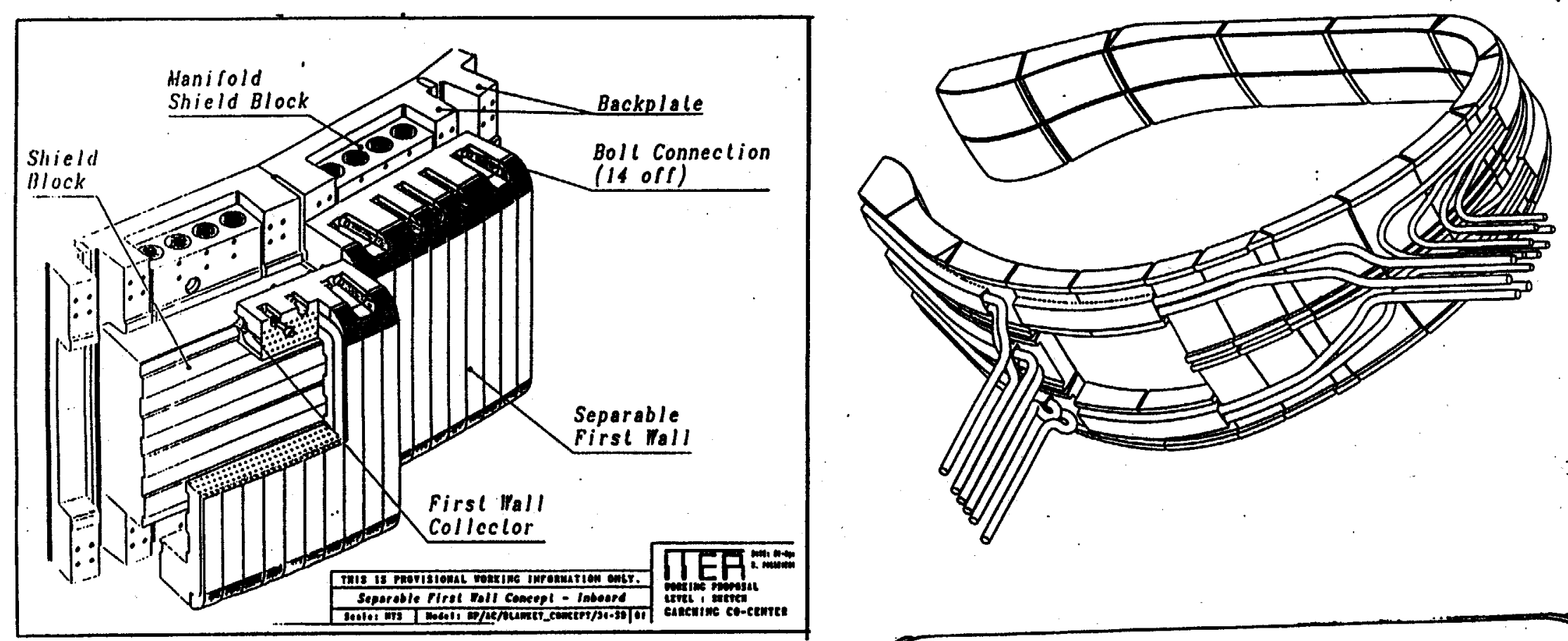

FW DESION LOADS SUMMARY

(For $1.4 \mathrm{~m}$ Pololdal Length Modula)

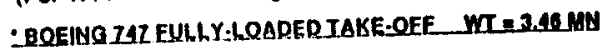

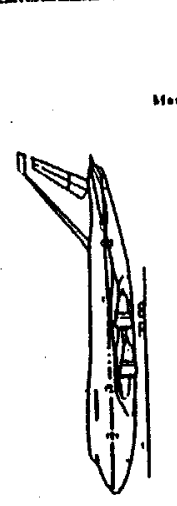

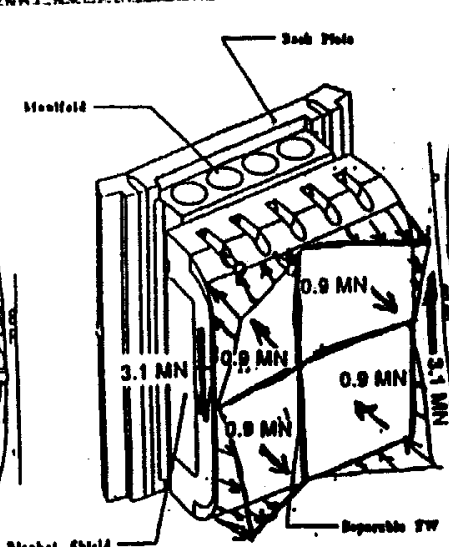

(1)

(1) EM LOAOS
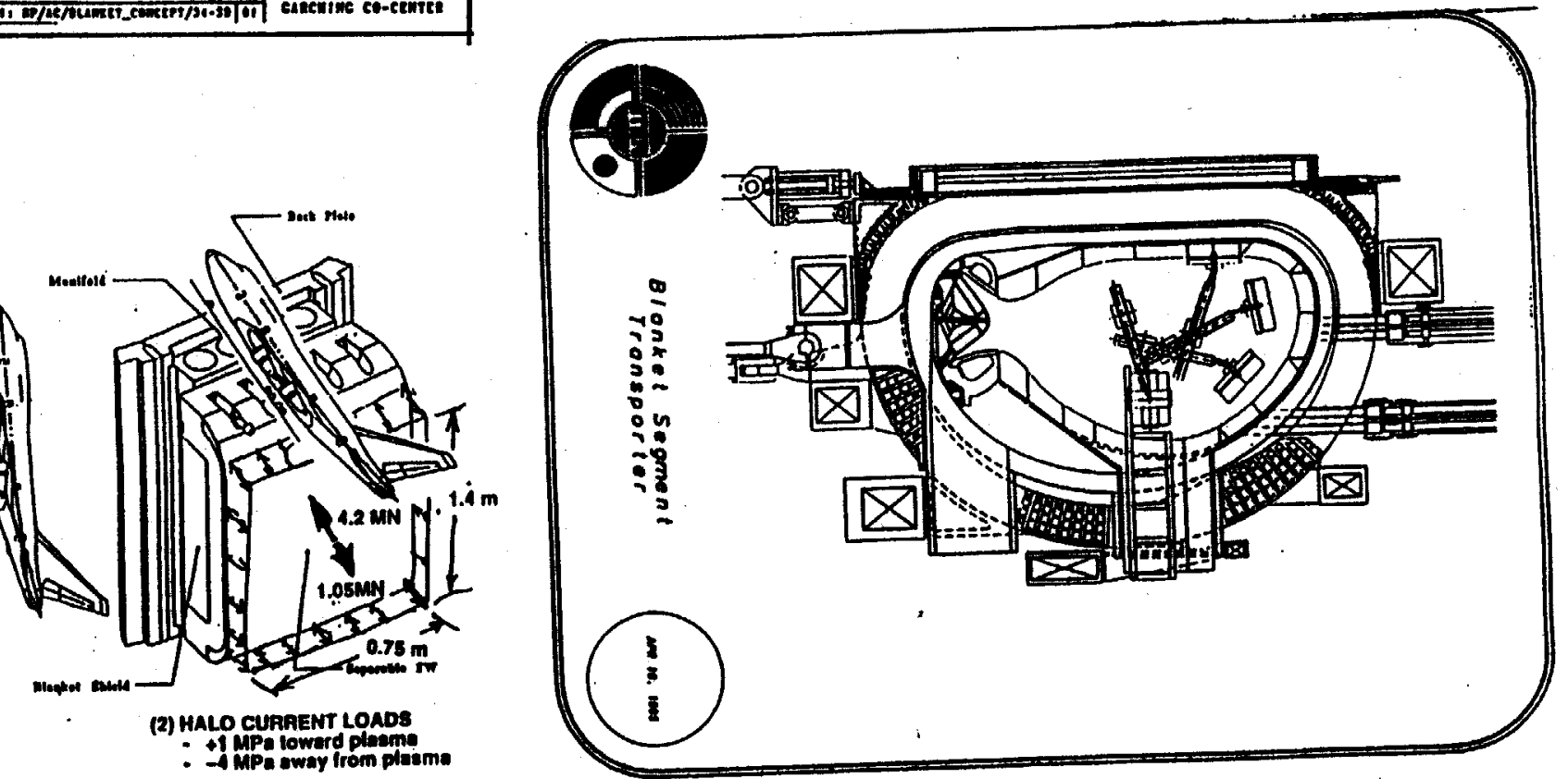

Fig. 2. Views of Design, Assembly and Maintenance for the ITER Blanket [35] 

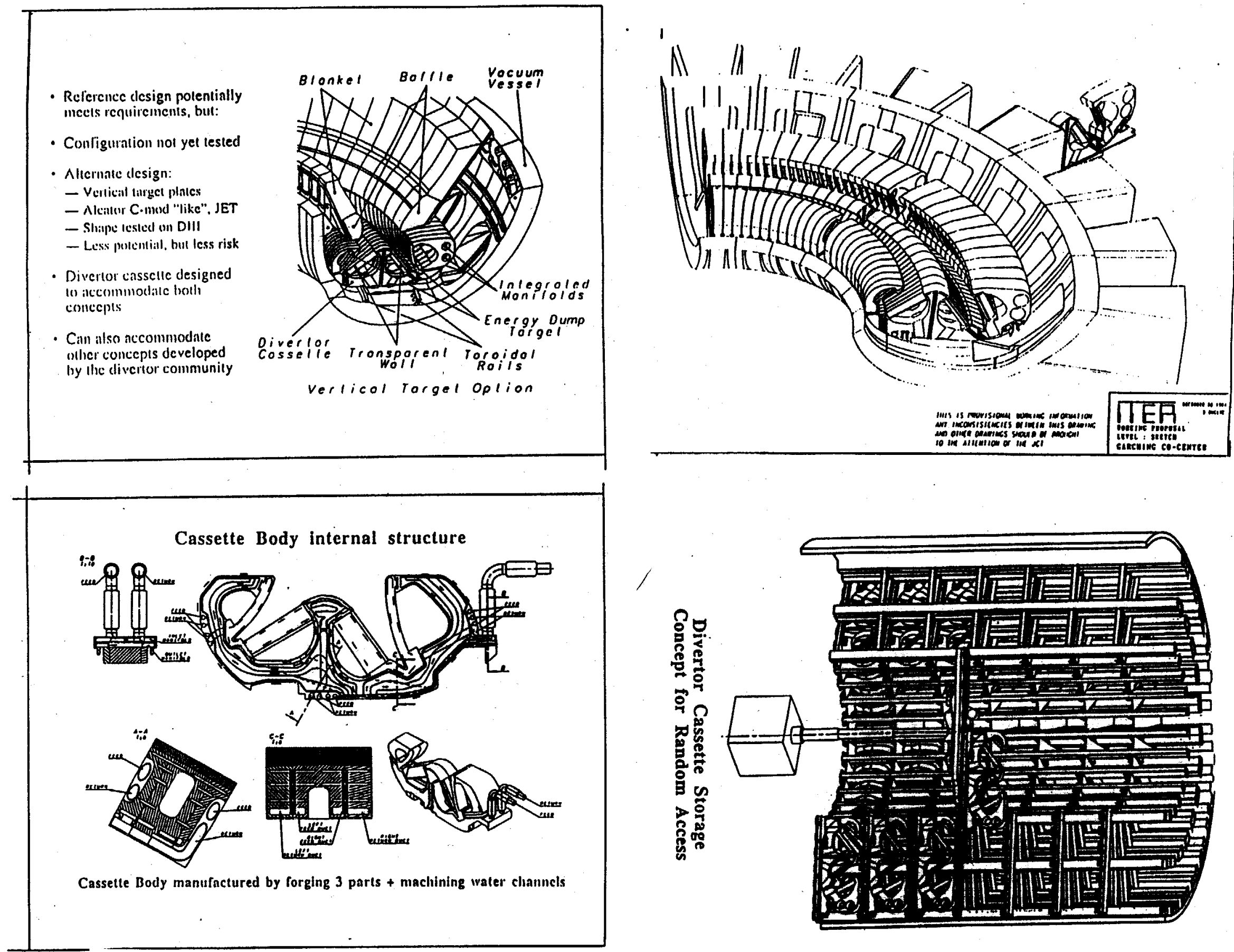

Fig. 3. Views of Design, Assembly and Maintenance for the ITER Divertor [35] 
Table 2. Required Blanket Reliability to Limit Unscheduled Outages to $\leq 5 \%$

(Tokamak blanket with 16 sectors and 9 segments per sector)

\begin{tabular}{|c|c|}
\hline \multicolumn{2}{|c|}{$\begin{array}{c}\text { MTTR }=\text { mean-time-to-repair } \\
\text { MTBF = mean-time-between failures }\left(=\left[\text { failure rate }\left(\mathrm{yr}^{-1}\right)\right]^{-1}\right)\end{array}$} \\
\hline & Reg'd MTBF for Each Blanket Segment \\
\hline MTTR = 1 week & 55 full power years \\
\hline MTTR = 1 month & 240 full power years \\
\hline MTTR = 6 months & 1440 full power years \\
\hline
\end{tabular}

inside the fusion power core. Abdou [36] has addressed similar issues in terms of the reliability requirements of the DEMO and beyond, and its impact on the requirements for a volumetric neutron source.

For a more quantitative view, we refer to a blanket availability study performed in 1991 by Bunde et al. [37]. Fig. 4 gives an illustration of an MFE reactor blanket similar to that analyzed by Bunde et al and is of a watercooled, solid ceramic breeder design with stainless steel structure and helium tritium purge (no detailed blanket illustrations were explicitly available in Bunde et al.'s paper). They approached the problem as generally as possible using a bottoms-up approach. First, this entailed an accounting of the individual components and assembly details of the blankets themselves, i.e. number of welds, total length of piping, number of pipe bends, etc. Following this, they applied a failure database for analogous components in present day systems such as fission reactors where an extensive database exists. When coupled with a fault tree analysis and estimates of mean down times for repair (i.e. MTTR), they were able to estimate an overall outage risk.

Fig. 5 illustrates the failure database employed by Bunde et al. in these studies, while Fig. 6 shows a breakdown of their estimation of the outage risk contributions between elements. Firstly note, unsurprisingly that the outage risk of this blanket system is high, i.e. greater than $40 \%$ alone. Second, about two-thirds of this outage is due to weld failures, particularly those between tubes and plates/tanks. Again, perhaps not surprising in view of there being $\sim 37,000$ butt welds and greater than $5 \mathrm{~km}$ of longitudinal welds (Fig. 4). Both Bunde et al and Abdou [36] have underlined the severe demands put on the blanket reliability for MFE power plants. 

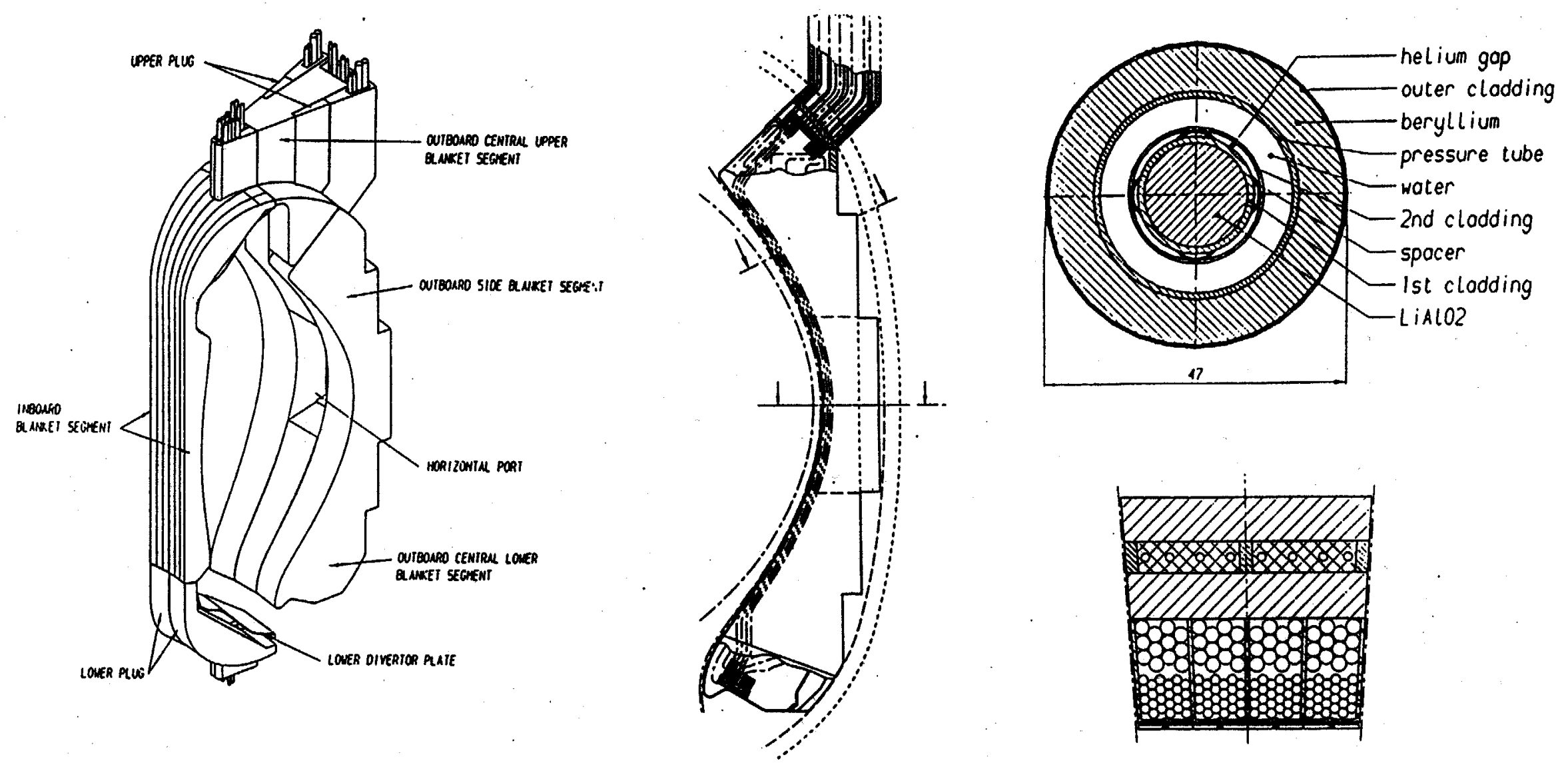

EQUATORILL SECTION

- Ceramic $\left(\mathrm{LiAlO}_{2}\right) \mathrm{T}_{2}$ breeder, $\mathrm{H}_{2} \mathrm{O}$-cooled, $\mathrm{He} \mathrm{T}_{2}$ purge, Be neut. multiplier, 316 s.steel structure

- Total length of straight pipes $=220 \mathrm{~km}$

- No. pipe butt welds $=37,000$

- No. pipe bends $=2300$

- Total length of longitudinal welds $=5.3 \mathrm{~km}$

Fig. 4. Tokamak Solid Breeder Blanket Similar to that Analyzed by Bunde et al. in the Availability Study of Ref. 37. 


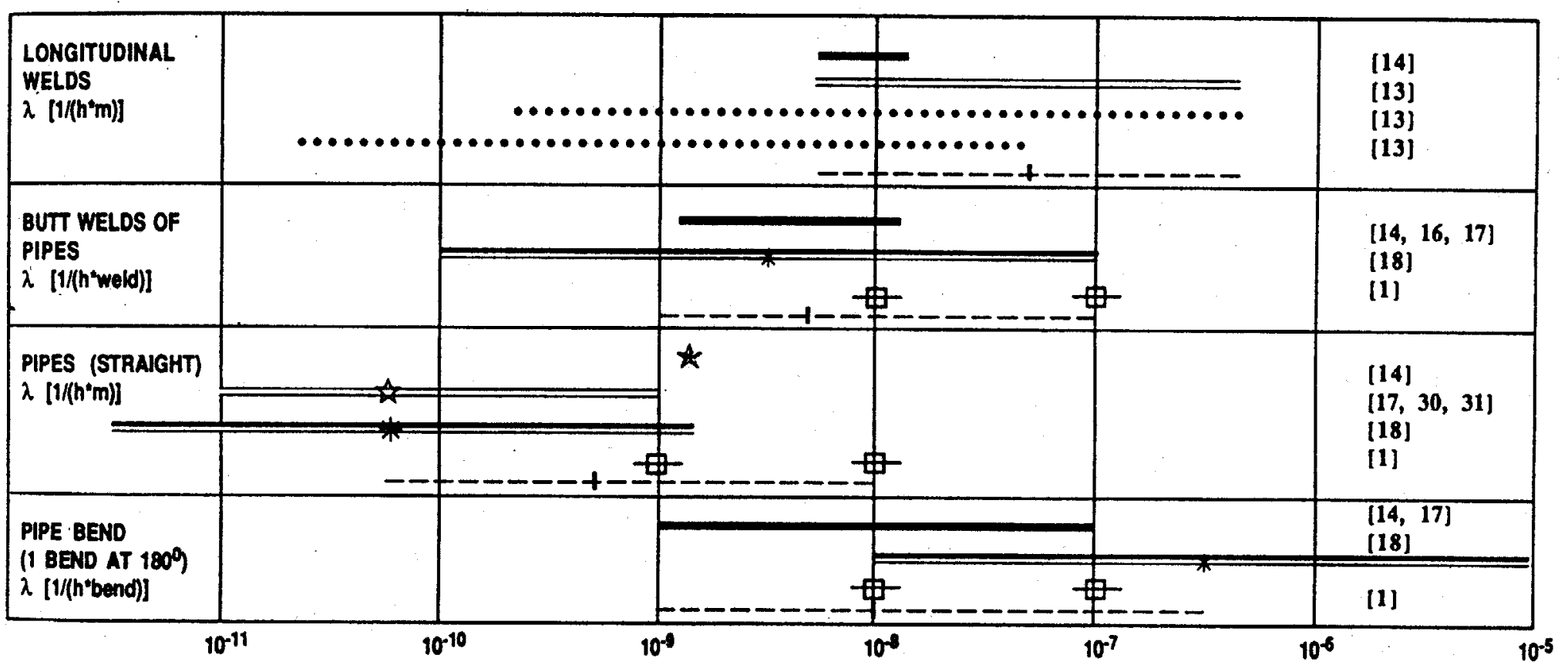

FALURE RATE $\lambda$ [dimension depending on them]

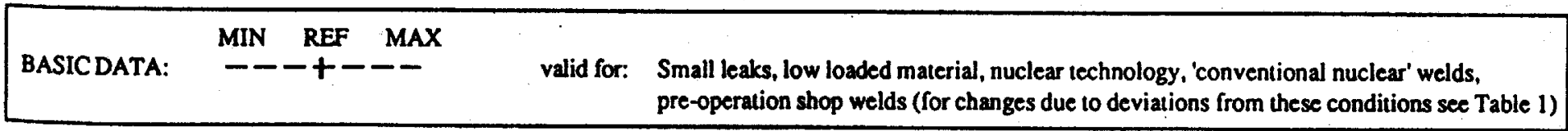

The types of lines and corresponding dots designate the various areas of information sources:

variety of heat transfer equipment
reactor pressure vessels
variety of nuclear technology heat transfer equipment ( $*=$ mean value)
conventional and nuclear vessels and piping. national (USSR) and intcrational (IAEA)

Fig. 5. Examples of Failure Databases Employed by Bunde et al. [37] 


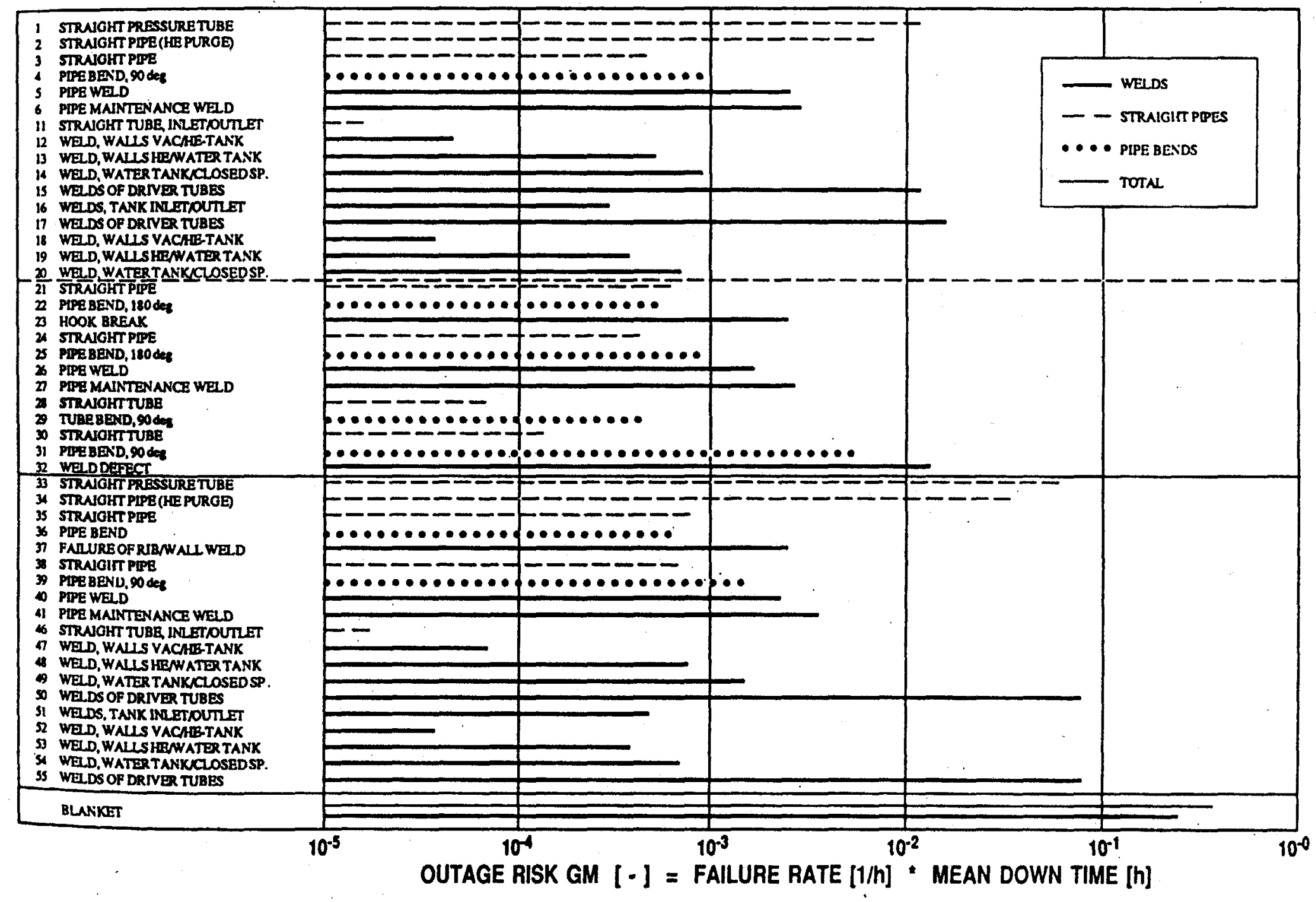

Fig. 6. Breakdown of Outage Risk Contributions Among Blanket Design Elements (Bunde et al [37]) 
As an alternative illustration of the "complexity" issues in MFE blankets, Table 3 compares some parameters for a generic MFE fusion blanket with analogous quantities for the core of typical fission pressurized water reactor. Note that, for a fair comparison, the MFE analogy to the core of a fission reactor inside the reactor pressure vessel should really include the complete fusion power core inside the cryostat boundary, including blankets, shield, divertor, vacuum vessel, TF coils, PF coils, etc. In the case of IFE, the equivalent "heat source" is the target chamber, beam transport and driver. Again, whether in terms of number of welds, amount of piping, number of penetrations, heat fluxes, etc., Table 3 underlines the "complexity" concerns surrounding the CRAM for MFE cores, especially since we really should also add the corresponding quantities for all the other systems internal to the cryostat.

Given the simple nature of a fission core, it is not surprising that the vast majority of unplanned outages in fission plants are due to failures outside the reactor vessel itself. Consequently because, like fission, a fusion power core comprises a heat source to boil water for a steam cycle, we must be prepared for similar outages external to the fusion power core for analogous systems. Again, this puts extreme demand on the scheduled and, in particular, unscheduled outage requirements for the fusion power core itself.

\section{Conclusions and Recommendations}

Probably the single largest potential advantage that IFE has over conventional MFE power plants is in the perception that it could achieve credible capacity factors. This accrues from three main sources:

1. The relative simplicity of the ICF reactor chamber made possible by decoupling the driver from the nuclear-grade thermal conversion system. Projected MFE reactors, by contrast, are a single integrated fusion power core with interlinked, hard to maintain components

2. The potential to use thick liquid walls thus providing for lifetime structural components and low activation inventory.

3. The potential to multiplex reactor chambers to provide operational redundancy*.

I This thick liquid wall would be backed by a low stress, non-nuclear steel wall

* This also has the associated advantage of permitting capital cost phasing. Note that MFE reactors could, in principle, also be multiplexed but as each fusion power core is essentially a self-contained unit, economy-of-scale penalties tend to negate any redundancy advantage. 
Table 3. Comparison of the "Complexity" of a Generic MFE Fusion Blanket with a Fission Corea

\begin{tabular}{|c|c|c|c|}
\hline & $\begin{array}{c}\text { Generic MFE } \\
\text { Fusion Reactor } \\
\text { Blanketa }\end{array}$ & $\begin{array}{c}\text { Typical PWR } \\
\text { Core }\end{array}$ & $\begin{array}{l}\text { Approximate } \\
\text { ratio: } \\
\text { Fission/Fusion }\end{array}$ \\
\hline Design & $\begin{array}{l}\text { Ceramic (LiA1O2) } \\
\text { breeder, water } \\
\text { cooled, Be multiplier, } \\
\text { He tritium purge, } \\
\text { ferritic steel structure, } \\
\text { concentric tubular } \\
\text { configuration }\end{array}$ & $\begin{array}{l}-180 \text { fuel clusters } \\
\text { each with a } 17 \times 17 \\
\text { fuel rod matrix. } \\
\text { Fuel=0.8cm dia } \mathrm{UO}_{2} \\
\text { pellets inside zircaloy } \\
\text { cladding of wall } \\
\text { thickness } 0.57 \mathrm{~mm} \\
\text { (22mills) } \\
\end{array}$ & - \\
\hline $\begin{array}{l}\text { Total length of straight } \\
\text { pipe (km) }\end{array}$ & $\sim 220^{k}$ & 21 & $\sim 0.1$ \\
\hline No. pipe butt welds & $-37,000^{k}$ & $0^{1}$ & $0\left(1.4^{1}\right)$ \\
\hline No. of pipe bends & $-2300^{k}$ & 0 & 0 \\
\hline $\begin{array}{l}\text { Length of longitudinal } \\
\text { welds }\end{array}$ & $\sim 5 \mathrm{~km}^{\mathrm{k}}$ & 0 & 0 \\
\hline Penetrations ${ }^{b}$ & -800 & $50^{\mathrm{j}}$ & -0.05 \\
\hline $\begin{array}{l}\text { Surface power density } \\
\left(\mathrm{MW} / \mathrm{m}^{2}\right)\end{array}$ & $-0.5^{c / ~} \sim 5^{d}$ & $0.6^{e}$ & $\sim 1^{f} / \sim 109$ \\
\hline $\begin{array}{l}\text { Peak fast neutron power } \\
\text { flux }\left(M W / m^{2}\right)\end{array}$ & $\sim 3^{h}$ & $\sim 0.015^{h}$ & $\sim 0.005^{i}$ \\
\hline
\end{tabular}

a. For a fairer comparison to the core of a fission reactor inside the reactor pressure vessel, the MFE analogy should really include the complete fusion power core inside the cryostat boundary, including blankets, shield, divertor, vacuum vessel, TF coils, PF coils, etc.

b, i.e. through bulkheads, shielding, cryostat, and pressure boundaries

c Peak, at first wall.

d Peak, at divertor.

e At fuel cladding surface.

f Relative to fusion first wall

g. Relative to divertor

h. Power flux of fast neutrons through the first wall (fusion) or cladding (fission)

i. Reason for this surprisingly small ratio is twofold: First, surface/volume ratio advantage for fission rel to fusion is a factor of $\sim 350$; second, only $\sim 5 \%$ of the $200 \mathrm{MeV}$ fission reaction energy appears as fast neutrons $\left(\left\langle\mathrm{E}_{\mathbf{n}}>\sim 2 \mathrm{MeV}\right)\right.$ whereas in fusion, $80 \%$ of the $17.6 \mathrm{MeV}$ fusion reaction energy appears as fast neutrons $\left(E_{n}=14.1 \mathrm{MeV}\right)$

j. Control rods

k. Data on pipe lengths and welds taken from Bunde et al [37]

1. There are end caps welded at the each of fuel rod, i.e. a total number of $\sim 52,000$ end cap welds. However, these are factory installed and inspected and considerably more reliable than on-site butt welds between tubes and plates. 
What, therefore, should be done to further quantify and, therefore, promote the CRAM advantages of prospective IFE power plants? There have been several quantitative studies of tokamak reactor reliability and availability based on bottoms-up accounting [see, for example, Refs 37-40]. The IFE program should consider performing analogous studies for an IFE power plant to highlight the advantages in as quantitative a manner that designs and databases will permit. This is a complex task as it requires full component documentation, fault tree construction, a failure and repair database, and Monte Carlo-like sampling analyses. Note, however, that we cannot, and should not, argue that databases are insufficiently developed for this task. For example, the IFE reactor chamber - probably the source of greatest concern regarding outage risk - is basically a steel vessel containing plates, tubes, pumps, and liquid coolant flows. Operating data is available at some level for all these individual components, much of it from direct power plant experience [37]

Accordingly, taking the HYLIFE-II studies of Moir et al. [21, 33, 34] as an excellent point-of-departure, we recommend the following work be performed:

1. Perform a comparative listing of the number of critical systems in a representative IFE power plant with analogous quantities for a typical MFE power plant and a representative fission plant. For example: length of straight pipe, number of welds, number of pipe bends, number of valves, number of pumps, number of parallel cooling systems, etc. Good detailed discussions of chamber fabrication and design can be found, for example, in Ref. 41.

2. Quantify, as far as possible, the CRAM advantages this IIFE power plant by calculating total outage risk in terms of MTBF/MTTR for the complete fusion specific plant defined in \#1 above.

3. Quantify, as far as possible, the advantages of thick liquid wall protection in terms of both scheduled and unscheduled (failure) outage of the chamber. Compare with thin wetted wall protection.

4. Quantify, as far as possible, the issues of multiplexing an IFE power plant, where a single driver is coupled to several reactor chambers, to promote the advantages of IFE regarding redundancy. This includes both the systems aspect of multiple chambers and capital cost phasing [see, for example, Refs 18-20] and also bottoms-up availability studies.

In closing, we underline that probably the single largest advantage of the IFE route to fusion energy is its potential for adequate reliability, maintainability and, therefore, availability of the fusion power plant. We should strive to promote this advantage on as quantitative a basis as possible. 


\section{Acknowledgments}

The author takes pleasure in acknowledging informative discussions with Ralph W. Moir, Wayne R. Meier, Ronald L. Miller, B. Grant Logan and Roger W. Carlson. This work was performed under the auspices of the U.S. Department of Energy by the Lawrence Livermore National Laboratory under Contract W-7405-Eng-48.

\section{References}

[1] ITER Technical Advisory Committee, Report on the Eighth TAC Meeting (TAC-8), ITER San Diego Joint Work Site, San Diego, CA, June 1995

[2] J.D.Galambos, et al., "Commercial Tokamak Reactor Potential with Advanced Tokamak Operation", Nucl. Fusion 35, 551 (1995).

[3] R.A.Krakowski, et al., "Lessons Learned from the Tokamak Advanced Reactor Innovation and Evaluation Study (ARIES)", Los Alamos National Laboratory, LA-UR-93-4217 (1993)

[4] C.G.Bathke et al., "A Systems Assessment of the Five Starlite Tokamak Power Plants" to be published in Fusion Technology (1996)

[5] J.P.Holdren, Science, 200, 168 (1978)

[6] L.M.Lidsky, "The Trouble With Fusion", Technology Review, p33, Massachusetts Institute of Technology (Oct 1983)

[7] K.H.Schmitter, "The Tokamak: An Imperfect Frame of Reference", p47 in Unconventional Approaches to Fusion, B. Brunelli and G. G. Leotta (Eds), (Plenum Press, NY, 1981)

[8] R.Carruthers, "Criteria for the Assessment of Reactor Potential", Ibid., p39

[9]. R.L.Hirsch, J. Fusion Energy, 5, 101 (1986)

[10] D.Pfirsh and K.H.Schmitter, "On the Economic Prospects of Nuclear Fusion with Magnetically Confined Plasmas", Max Planck Institut Fur Plasmaphysik, Garching, IPP 6/271 (1987)

[11]. C.Sweet, "Criteria for the Assessment of Fusion Power", Energy Policy, 17, 419 (Aug 1989)

[12]. J.Reece Roth, "A Critical Evaluation of the DT Tokamak as a Power Plant for the Electric Utilities", Proc 13th Symp on Fusion Engineering, Knoxville, TN, Oct 1989, IEEE, 89CH2820-9 (1990) 
[13]. W.D.Kay, "The Politics of Fusion Research", Issues in Science and Technology, p40, Winter 1991-92

[14] C.G.Bathke et al., "A Need for Non-Tokamak Approaches to Magnetic Fusion Energy", 17th Symp. 'on Fusion Technology, Rome, Italy, Sept 1992

[15] L.J.Perkins, "The Restructured Fusion Program and the Role of Alternative Fusion Concepts", Testimony to the US House of Representatives Committee on Science, Lawrence Livermore National Laboratory , UCRL-ID-123417 (1996)

[16] T.Sweeney and L.Goldman, "Toroidal Field Coil Replacement for the International Thermonuclear Experimental Reactor", Bechtel Inc, September 1991

[17] R.W.Moir, Lawrence Livermore National Laboratory, private communication (1996)

[18] W.R.Meier et al., "Economic Studies for Heavy Ion Fusion Electric Power Plants", Lawrence Livermore National Laboratory UCRL-94335 (1986)

[19] W.R.Meier et al. "Economics and Other Figures of Merit", Chpt 7 in Energy from Inertial Fusion, International Atomic Energy Agency (1995)

[20] B.G.Logan et al, "Requirements for Low-Cost Electricity and Hydrogen Fuel Production from Multiunit Inertial Fusion Energy Plants with a Shared Driver and Target Factory", Fusion Technology, 28, 1674 (1995)

[21] R.W.Moir et al., "HYLIFE-II: A Molten-Salt Inertial Fusion Energy Power Plant Design", Fusion Tecnology 25, 5 (1994)

[22] List of Scheduled Outages at US Nuclear Power Plants, Nuclear News 36, No. 1, 31 (1993)

[23] List of Scheduled Outages at US Nuclear Power Plants, Nuclear News 36, No. 9, 37 (1993)

[24] List of Scheduled Outages at US Nuclear Power Plants, Nuclear News 37, No. 1, 40 (1994)

[25] List of Scheduled Outages at US Nuclear Power Plants, Nuclear News 37, No. 9, 33 (1994)

[26] List of Scheduled Outages at US Nuclear Power Plants, Nuclear News 38, No. 1, 35 (1995) 
[27] List of Scheduled Outages at US Nuclear Power Plants, Nuclear News 38, No. 9, 26 (1995)

[28] E.M.Blake, "US Capacity Factors: Crowding the Ceiling", Nuclear News 39, No. 6, 24 (1996)

[29] World List of Nuclear Power Plants, Nuclear News 39, No. 3, 40 (1996)

[30] D.Cook, Commonwealth Edison Co., Quad Cities Power Plant, Cordorva, $\mathrm{IL}$, private communication (1996)

[31] S.Rosen, Houston Lighting and Power Co., private communication (1996)

[32] L.El-Guebaly, University of Wisconsin, Madison WI, private communication (1996)

[33] R.W.Moir, "Improvements to the HYLIFE-II Inertial Fusion Power Plant Design", Fusion Technology, 26, 1169 (1994)

[34] R.W.Moir, "IFE Power Plant Design Strategy", to be published in Fusion Technology (1996)

[35] ITER Technical Advisory Committee Informal Technical Review on InVessel Systems and Related Physics, TAC-95-16, ITER Garching Joint Work Site, Garching, Germany (1995)

[36] M.A.Abdou, "A Volumetric Neutron Source for Fusion Nuclear Technology Testing and Development", Fusion Eng. and Design, 27, 111 (1995)

[37] R.Bunde at al., "Reliability of Welds and Brazed Joints in Blankets and its Influence on Availability" Fusion Eng. and Design, 27, 111 (1995)

[38] R.Bunde, "Reliability and Availability of the Next European Torus", Fusion Technology, 14197 (1988)

[39] Z.Musicki, "Availability Analysis of Fusion Plants Employing a Monte Carlo Simulation Computer Code", PhD Thesis, University of Wisconsin, Madison (1984) WI, University Microfilms International, AnnArbor, MI

[40] Z.Musicki et al, "The Fusion Engineering Database", proc 11th IEEE Symp. on Fusion Engineering, Austin, TX (1985)

[41] P.A.House, "HYLIFE-II Reactor Chamber Design Refinements", Fusion Technology 26, 1178 (1994) 


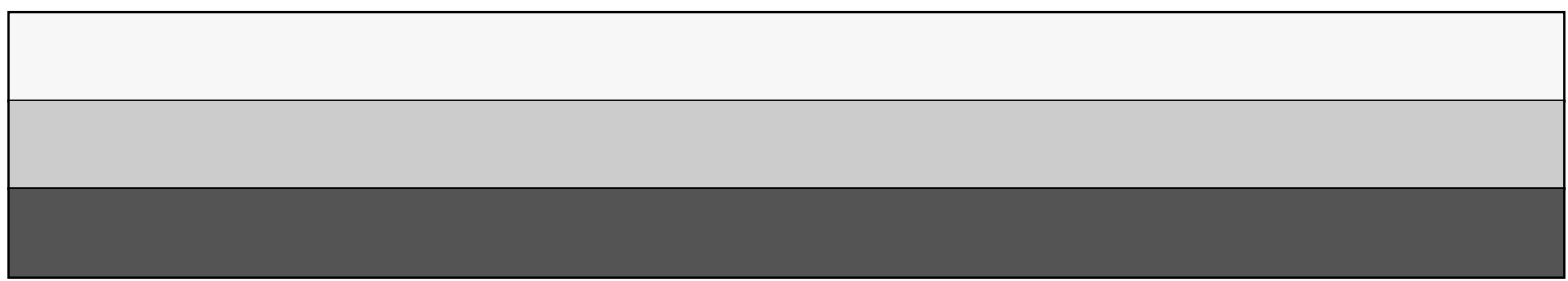

